\title{
De Soweto à Ceilândia: siglas de segregação racial.
}

\author{
LEMOS, Guilherme Oliveira ${ }^{1}$ \\ ${ }^{1}$ Doutorando pelo Programa de Pós-Graduação em História, \\ Universidade de Brasília, Brasília, Brasil \\ guilhermeolemos@gmail.com
}

\section{Resumo}

A proposta desse trabalho é pensar relações comuns ou, pelo menos, aproximadas entre os processos e os instrumentos de segregação urbana racial, generificada e social nos núcleos de Soweto (Johanesburgo - África do Sul) e Ceilândia (Distrito Federal - Brasil) durante as décadas de 1950 e 1970. Para tanto, comparamos os dois processos de remoção das populações dos centros para as periferias e a (re)invenção dos tipos corpóreos ("candango", "black", "african", "coloured") destinados a ocupar os limites da não-vida, ou seja, as chamadas cidades satélites. Metodologicamente, a pesquisa, de caráter inicial, fez-se através da análise indiciária e comparativa de documentos oficiais, relatos orais e bibliografia referentes às duas cidades. A aproximação analítica/histórica entre esses casos se tornou possível através do conceito de necropolítica e da correlação entre escravidão, colonialismo e apartheid: três eventos imaginados historiograficamente como distintos, mas nos quais a dissociação do ser ao direito de sua própria vida rompe as barreiras do tempo e, no caso Soweto-Ceilândia, as fronteiras do Atlântico.

Palavras-Chave: segregação racial: biopolítica: necropolítica: urbanização: Soweto: Ceilândia.

\begin{abstract}
The purpose of this work is to think about common or at least approximate relationships about the processes and instruments of racial and social urban segregation in Soweto (Johannesburg - South Africa) and Ceilândia (Distrito Federal - Brazil) during the 1950s and 1970s In order to do this, we compare two processes of removal of populations of centers to peripheries and the (re)invention of corporeal types ("candango", "black", "african", "colored") to occupy the limits of no-life in satellite cities.

Methodologically, this initial research was made through indexical and comparative analysis of official documents, oral reports and bibliography referring to the two cities. The analytical / historical approach between these cases has become possible through the concept of necropolitics and the correlation between slavery, colonialism and apartheid: three events pictured as distinct by historiography, but in which the dissociation of the human being to the right of his own life breaks the barriers of time and, in the SowetoCeilândia case, the borders of the Atlantic.
\end{abstract}

Key-Words: racial segregation: biopolitics: necropolitics: urbanization: Soweto: Ceilândia. 


\section{Introdução}

\subsection{Caminhos}

Começo esse artigo fazendo um exercício de reflexão sobre os caminhos que me trouxeram ao tema, que hoje é central no desenvolvimento do doutorado em andamento. Toda pesquisa só é possível com grandes doses de subjetividade e entendo que a história só pode ser construída no entrelaçar de várias narrativas, fruto dos pontos de vista de múltiplos sujeitos.

Pensar a relação "Cidades-Satélites"/Plano Piloto $^{1}$ no Distrito Federal sempre foi uma constante na minha formação como pessoa. Sou de uma geração de netos e netas de migrantes que se fixaram nas satélites e aqui construíram suas histórias. Cresci no início da década de 1990 no limite entre Taguatinga ${ }^{2}$ e Ceilândia. Meus avós paternos tiveram maior vivência na formação inicial das satélites e muitas vezes escutei histórias do meu pai sobre como meu avô, durante os anos trabalhados como pedreiro na construção da capital, sobreviveu à "Chacina da $\mathrm{Pa}$ checo Fernandes" 3 se escondendo em baixo do beliche enquanto os policiais da G.E.B. (Guarda Especial de Brasília) metralhavam os revoltosos. Muitas outras história escutei da minha avó, dona Maria Eustáquia, mulher negra, que enfrentou violências raciais e de gênero para se formar em pedagogia e oferecer condições meIhores aos seus filhos.

Mas, os processos de reflexão entre formação das satélites e as histórias que me constituíam surgiram mais tarde. Como tantas outras trajetórias negras universitárias no Brasil, eu só me deparei com as discussões de identidade racial durante o ensino médio quando - no início da implementação das cotas raciais na Universidade de Brasília e dos debates que isso suscitava - me percebi homem negro e, portanto, cotista.

\footnotetext{
1 O Distrito Federal brasileiro é dividido em Regiões Administrativas, onde Brasília (Plano Piloto) é a região central $e$ as demais regiões circundantes eram denominadas de "Cidades-Satélites". As satélites, em sua maioria, surgiram para abrigar pessoas que vieram trabalhar, em condições subalternas, na construção da capital.

2 Primeira satélite criada em 1958 para abrigar famílias da Vila Sara Kubitschek. Essas famílias chegam nas primeiras semanas de junho de 1958 após uma grande seca no nordeste. Impedidas pela GEB (Guarda Especial de Brasília) de entrar na Cidade Livre, fixaram acampamento ao redor do terreno e se apropriam do nome da primeira dama para legitimarem a ocupação (HOLSTON, 2010, p.261).

3 Chacina ocorrida no acampamento da empreiteira Pacheco Fernandes para abafar as revoltas pela péssima condição de moradia e comida.
}

Além disso, a chegada à universidade me fez refletir sobre as raras visitas ao Plano Piloto e como a sigla UnB tinha uma representação imagética: tal como as palavras alma ou espírito. Acreditava na existência próxima, mas não me parecia tangível.

No mestrado, trabalhei com historiografia e teorias africanas abrindo um leque de possibilidades para pensar a história e os processos alheios a nossa formação tão euro centrada. Contudo, senti a necessidade de ir além e a ideia me veio logo no final da elaboração da dissertação numa conversa informal com o amigo Leandro Bulhões. Discutíamos a total ausência de professores do departamento pesquisando a história do Distrito Federal. Somando os conhecimentos construídos entre família/academia e esse campo a ser explorado, me veio a possibilidade de unir as experiências sul-sul - principalmente depois da leitura de Hountondji (2008) e Mbembe (2001) indicadas por Wanderson Flor na qualificação.

Ademais, devo ressaltar aos leitores o caráter interdisciplinar deste artigo. Muitas vezes permeado com termos próprios do léxico da história, sociologia e antropologia, ele é também um esforço para estabelecer diálogos com as teorias sobre espaço e urbanismo.

\subsection{Locais}

$\mathrm{Na}$ cidade de Johanesburgo, um modelo de segregacionismo urbano já existente no início do século $X X$, ainda durante os anos coloniais, foi aperfeiçoado após a independência. O bairro de Soweto - cujo nome é uma sigla que advêm da abreviação South West Townships, ou seja, "Bairros do Sudoeste" - fora projetado para realocar trabalhadores africanos negros residentes nas áreas centrais e resulta de um longo processo que tem influência tanto do colonialismo britânico quanto do regime republicano africâner. É nesse novo regime, porém, que a reconfiguração e definição do território ocorrerá como consequência das políticas segregacionistas nas décadas de 1950-1960 após a independência sul-africana de 1961, referendada por meio do controle do ultranacionalista africâner na política.

No mesmo período, observaremos no Brasil o fenômeno da expansão urbana na região centro-oeste do país com a transferência da nova capital. A construção de Brasília estimulou um fluxo migratório e mobilizou famílias nordestinas, pretas e partas, principalmente, em torno dos trabalhos na área da construção civil. A 
princípio, não existia um planejamento para a fixação desses homens e mulheres na nova capital e os reajustes no projeto urbano foram surgindo a partir das políticas de realocação dos assentamentos que se formaram na região central de Brasília. Dentre elas, a cidade de Ceilândia, fruto da remoção em 1971 de residentes da Vila do IAPI, e cujo nome tem origem na sigla da Campanha de Erradicação de Invasões (C.E.I.).

A proposta desse trabalho é, portanto, procurar reflexões comuns ou, pelo menos, aproximadas sobre os processos e os instrumentos de segregação racial, de gênero e social nas cidades de Soweto e Ceilândia nas décadas de 1950 e 1970 , tendo em vista como os processos históricos, as políticas de Estado e as múltiplas formas de exercício do poder podem recair sobre uma biopolítica e uma necropolítica.

A pesquisa se encontra em fase inicial e a visita de campo a Soweto e aos demais arquivos sulafricanos foi realizada apenas no momento de finalização deste artigo. Logo, em grande parte do tempo de escrita fiquei restrito às fontes disponíveis no Arquivo Público do Distrito Federal e nas bibliografias e filmografias para o caso de Ceilândia e Brasília. No que se refere a Soweto, o exercício foi um tanto árduo e a pesquisa de fontes foram feitas com base nas entrevistas e fotografias encontradas no Historical Papers Archive da University of Witwatersrand e nos arquivos e biografias disponíveis no domínio publico http://archiev.org.

\section{Biopolítica e Necropolítica: pen- sando as segregações urbanas.}

\subsection{Foucault e o conceito de biopoder.}

O conceito de biopolítica foucaultiana centrouse na ideia de biopoder. Para ele, ao observamos o exercício do poder do Estado sobre muIheres e homens enquanto seres viventes no século XIX assistimos "uma espécie de estatização do biológico" (FOUCAULT, 2002, p. 218). $O$ direito de soberania que outrora consistia apenas em "fazer morrer e deixar viver" encontra um novo direito, que não atrapalha o primeiro, mas o atravessa e o modifica, com um poder inverso de "fazer viver e deixar morrer". Essa nova disciplina não se aplica apenas ao ser humano/corpo, mas também ao ser humano/espécie. Assim, o interesse central dessa nova tecnologia diz respeito a um conjunto de processos de natalidade, mortalidade e longevidade, constituídos na segunda metade do século XVIII. Um controle sobre as epidemias que assolam as populações conduziram os saberes médicos à função crucial da higiene pública e da sanitização das cidades, diferente dos processos anteriores de disciplinaridade dos corpos individuais. Em síntese, o fenômeno da biopolítica com base no biopoder consiste em "tomar conta da vida, dos processos biológicos do homem/espécie e de assegurar neles não uma disciplina e sim uma regularização" (FOUCAULT, 2002, p. 223).

No entanto, essas duas séries: a) corpo - organismo - disciplina - instituições; e b) população - processos biológicos - mecanismos regularizadores - Estado; não estão em oposição. A norma será o elemento em que disciplina e regularização atuam concomitantemente, permitindo disciplinar o corpo e os eventos aleatórios de uma multiplicidade biológica. Assim, dizer que o poder, no século XIX, se apossou da vida é dizer que: "chegou a cobrir toda a superfície que se estende do orgânico até o biológico" FOUCAULT, 2002, p. 229).

Mas, então, "como pode deixar morrer esse poder que tem o objetivo essencial de fazer viver?". O ponto de inflexão entre vida e morte na biopolítica seria o racismo. Para Foucault, foi o surgimento do biopoder que inscreveu o racismo nos mecanismos de Estado. O racismo, sendo a secção entre os que devem morrer e os que devem viver numa hierarquia de espécie, estabelece sua função primordial no biopoder. Por conseguinte, exerce também sua segunda função de "quanto mais deixar morrer, mais viverá", ou seja, "se queres viver, é preciso que faça morrer, é preciso que possa matar [o inimigo]", assim, a morte de um "tipo racial" assegura a vida de outro. Raça e racismo tornam aceitáveis as mortes numa sociedade normalizadora e "na medida em que o Estado funciona na modalidade de biopoder, sua função mortífera só pode ser assegurada pelo racismo". Essa condição pela qual se exerce o direito de matar não ocorre apenas com assassinatos diretos, mas também com assassinatos indiretos: expondo à morte, multiplicando os riscos, expulsando, rejeitando e ignorando (FOUCAULT, 2002, p. 230233).

É exatamente nesse último caso que as realocações e segregações urbanas planejadas pelo Estado estabelecem paralelismos com o biopoder e o racismo. No entanto, as reflexões de Foucault estão ainda restritas ao espaço urbano europeu e, mesmo quando o autor pontua o racismo, refere-se às experiências nazifascistas; ou, quando aponta a biopolítica no espaço colonial, a coloca como uma experiência lon- 
gínqua. Por isso, Mbembe, apoiado nessa conceptualização, a reformula pensando como nos territórios coloniais impera a necropolítica, uma vez que o espaço colonial representa o lugar onde soberania consiste num exercício de poder a margem da lei e onde a "paz" só pode ter a face de uma "guerra sem fim" (MBEMBE, 2006, p.37). Mais ainda, na visão de Mbembe (2001, p.196) a relação entre escravidão, colonialismo e apartheid tem sua continuidade e unicidade na medida em que esses eventos estabelecem uma dissociação entre direito à vida e à propriedade do corpo, sobretudo o negro. Nesses três eventos o signo "negro" foi marcado e transformando em homemmercadoria, homem-metal, homem-moeda (MBEMBE, 2013, p. 300).

\subsection{A necropolítica de Achille Mbembe.}

No território colonial tardio, a cidade (township) implica severas restrições da produção de negras e negros para o mercado nas zonas brancas, proibições de residências negras nos setores brancos, controle do fluxo urbano e rejeição da cidadania (MBEMBE, 2006, p.44). Nas fronteiras internas do território colonial, é empregada a linguagem da violência pura. Para exemplificar, Mbembe evoca a descrição de Fanon em Os Condenados da Terra:

\footnotetext{
A cidade do indígena, a cidade negra, a "cidade do colonizado, ou ao mesmo tempo a medina" ou bairro árabe, a reserva é um lugar de má fama, povoado por homens com má fama. Ali se nasce em qualquer parte, de qualquer maneira. Se morre em qualquer parte, de qualquer coisa. É um mundo sem intervalos, os homens estão um sobre os outros, as casas umas sobre as outras. A cidade do colonizado é uma cidade faminta, faminta de pão, de carne, de sapatos, de carvão, de luz. (FANON apud MBEMBE, 2006, p. 46).
}

Tanto a cidade colonial tardia quanto a cidade colonial da era moderna combinaram o disciplinário, a biopolítica e a necropolítica. A violência que era infligida aos corpos negros na escravidão (homem-mercadoria) se transformou num habitus colonial: "um capricho do ato puramente destruidor que aspira instigar o terror" (MBEMBE, 2006, p.33). Esse habitus, entendido no conceito de Norbert Elias (1990), constituiu uma das camadas da personalidade do indivíduo colonizador e produziu, mais tarde, um Estado que empreende uma tarefa de "civilizar" as formas de assassinar e de atribuir objetivos racionais do ato de matar. Seja por assassina- tos diretos (violência pura) ou indiretos (remoções forçadas, cerceamento das necessidades básicas, etc.) as cidades coloniais e póscoloniais são, nessa perspectiva, espaços de livre exercício do terror. Esse estado de terror ao qual são submetidos os territórios coloniais retroalimenta o imaginário colonialista de espaços selvagens e de morte, com ficções que criam ilusão do real. Consequentemente, as guerras nos espaços coloniais colocam o conquistador frente a um "inimigo absoluto": para haver paz nesses espaços é necessário levar a civilização com domínio total sobre esse inimigo inventado (MBEMBE, 2006, p. 41).

Mas como, porém, Soweto e Ceilândia se relacionam com biopolítica e necropolítica? Veremos que o histórico dessas cidades, apesar de suas especificidades, está intimamente ligado às políticas de remoção e "limpeza racial" dos centros urbanos promovidos pelo Estado entre 1950-1970.

\section{Segregação Racial nos espaços urbanos: de Soweto à Ceilândia.}

\subsection{Soweto}

A necessidade de controle e as violências diversas infligidas sobre negros e negras na África do Sul remontam ao último quartel do século XIX. A "lei do passe", criada em 1872 sob exigência dos brancos proprietários de minério na cidade de Kimberley, foi uma tentativa de reduzir o poder de negociação relativa aos salários dos mineiros negros. A lei exigia que todos os trabalhadores tivessem de possuir um passe informando se "os titulares estavam ou não autorizados a trabalhar na cidade, se tinham ou não completados suas obrigações contratuais e se podiam ou não sair da cidade" (FONSECASTATTER, 2011, p. 154). Apesar da letra da lei não especificar raça e etnia, na prática ela era apenas aplicada aos negros e negras, que em sua maioria eram migrantes em constante movimento na busca de melhores condições salariais. Acontecia que tais trabalhadoras e trabaIhadores mudavam constantemente dentro dos campos diamantíferos de Kimberley numa busca, quase sempre bem-sucedida, de melhores remunerações. Além disso, criaram-se tribunais especiais para os julgamentos dos infratores dessa lei; zonas reservadas para as habitações africanas; e, por fim, em 1886, adotam-se os regimes dos compounds, "bairros" ou prisões fechadas onde os mineiros eram guardados e obrigados a permanecer até o final dos contratos de trabalho. 
As políticas coloniais britânicas no território sulafricano já sinalizavam o que, mais tarde, seria o apartheid institucionalizado após a vitória do primeiro ministro Daniel François Malan com o Herenigde Nacacionaly Part (HNP), em 1948. As disputas entre britânicos e descendentes holandeses (africâneres) na África Austral foram uma constante no século XVIII, XIX e só encontraram solução no século XX. A vitória de Malan representou, na política para brancos e brancas, a autonomia africâner frente a administração inglesa ao mesmo tempo em que, para negras e negros, um enrijecimento e institucionalização das políticas do apartheid. O HNP, inclusive, surge como resposta ultranacionalista africâner em relação às posições pró Inglaterra do United Party na Segunda Guerra Mundial (DUBOW, 2014, p. 18-31).

Soweto surge como herança do passado colonial da era contemporânea. Ainda sob administração britânica, foram criados os bairros de Klipspruit (1904) e de Orlando (1931) para realocar os africanos com o objetivo de limpeza dos bairros pobres que concentravam trabalhadores próximos ao centro de Johanesburgo. Orlando foi o primeiro bairro construído naquilo que, mais tarde, em 1963, será o coração de Soweto. A remoção dessas famílias para essa área foi propagandeada pela administração colonial como um "paraíso", mas no fundo as acomodações eram de miseráveis condições e de uma distância considerável em relação ao centro de Johanesburgo. Entre os anos 1950 e 1960 , as remoções para os bairros do sudoeste já estavam quase completas, não sem resistência. Nos anos 1960 uma forte campanha mobilizada pela ANC (African National Congress) contra o passe de acesso aos centros provocou protestos que foram ferozmente reprimidos num famoso episódio em que a polícia abriu fogo matando 69 pessoas entre mulheres, homens e crianças em Sharpeville. Esse massacre silenciou significativamente os protestos durante uma década e novos protestos só reacenderam em 1976, na famosa "insurreição de Soweto" quando a polícia abriu fogo contra uma multidão de 10 mil estudantes que marchavam da Naledi High School até o Orlando Statidum (ALEXANDER et al., 2013, pp.35-55). Essas repressões revelam como o Estado implicava uma necropolítica nas fronteiras coloniais onde a força policial tem a autorização estatal de controle sobre aquelas e aqueles que são colocados, objetiva e subjetivamente, à margem da lei.
Outra remoção que perpetra desses espaços de apartheid ocorreu em 1955. A transferência das famílias de Sophiatown para Soweto registra em fotografia e memórias a expropriação, a derrubada de casas e a formação de espaços distantes dos centros, desumanizando sujeitos cuja mão de obra é barateada para os empregadores brancos.

Figura 1: Fotografia das remoções em Sophiatown

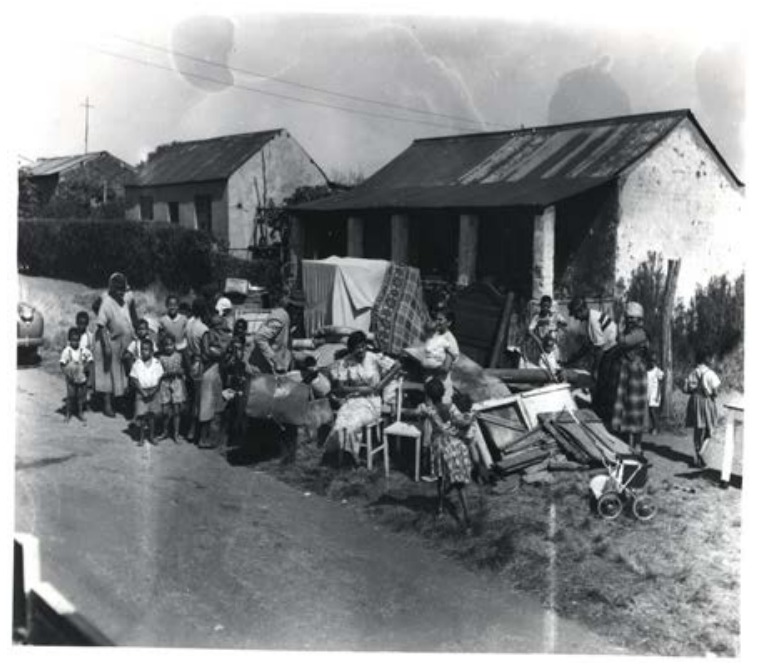

Fonte: Historical Papers Reseach Archive, University of the Witwatersrand, 1955

Sophiatown representava um centro de produção cultural de escritores, músicos do jazz e do blues e, ainda hoje, os habitantes que retornaram ao bairro após o apartheid, preferem resgatar essas memórias de agitação cultural da cidade criando alternativas para a narrativa do apartheid (ERLANK, 2015; NAIDOO, 2015). Talvez, sua intenção seja afastar o sentimento grande de perda como relata Victor Mohkine: "Quando ando por Sophiatown, eu ainda tenho um profundo sentimento de perda. Não penso que isso será erradicado" (CORRIGALL, p.2).

Em outra entrevista disponível em áudio, Mohkine relembra o que ocorreu esse processo: "o governo removeu as pessoas de Sophiatown [...] tudo foi destruído, escolas, igrejas, casas, lojas [...] tudo foi destruído, exceto a igreja Christ the King" (MOHKINE, 2011). O cenário de guerra fora instaurado. Pessoas desabrigadas, casas, escolas e estruturas urbanas postas a baixo: "a maneira como eles fizeram isso foi como uma situação de guerra; havia caminhões grandes e policiais montados em todo bairro", descreve Mohkine (CORRIGALL, p. 4).

O que se evidencia aqui é a operação da total transformação de um espaço urbano já estruturado (casas de alvenaria, escolas, igrejas, clubes) em um local de terror, de desapropriação. 
Dorothy Rosenburg, sul-africana coloured, também relembra como ocorreram essas remoções:

\begin{abstract}
"uma certa manhã, quando acordamos com um barulho perturbador, isso era por volta de 4 a.m. [...] chegaram grandes caminhões de guerra e eles não removeram as famílias coloureds, eles removeram todas as pessoas negras. Coloured, indianos e chineses ficaram para trás. Mas nós tivemos de procurar nosso próprio lugar para ficar"
\end{abstract}

De fato, o Group Areas Act de 1950, principal arma legal do governo segregacionista, determinava que pessoas de "raças" diferentes não poderiam ocupar o mesmo espaço urbano. No caso de Sophiatown, muitas pessoas negras foram realocadas nas matchbox (minúsculas acomodações que, devido ao seu tamanho ficaram conhecidas como caixas de fosforo, em inglês, matchbox) de Meadowlands numa média de 16 km de distância do centro.

Tanto a imagética dessas remoções quanto a criação de distâncias e corpos abjetos remonta ao Distrito Federal entre os anos 1950 e 1970. Aqui, no entanto, a historiografia e a sociologia trataram de nivelar os corpos candangos como trabalhadores braçais. Essa agência do conceito candango como homem bruto/massa trabaIhadora, foi estimulada tanto pelas teorias que versam sobre proletariado e luta de classes quanto pela sociologia brasileira de Gilberto Freyre, que encontra na miscigenação a base das resposta para a formação do Brasil.

Para remontar às raízes dessa influência, podemos citar apenas um dos textos mais famosos de Freyre, um relatório encomendado pela ONU em ocasião do ciclo de debates sobre o apartheid sul-africano - realizado em 1966, ironicamente, em Brasília. Nele, o sociólogo elenca sua teoria como solução para o "contraste mais violento" em relação à realidade brasileira. Além de apagar o corpo negro unificando-o em uma narrativa miscigenacionista "o negro no Brasil não é um negro brasileiro, ele é um brasileiro" (2003, p.339), Freyre faz uma paráfrase com a famosa frase de Marx (Proletários do mundo, uni-vos!): "Por que os homens e mulheres de raça misturada não se uniram aos brasileiros, intensiva e extensivamente contemporâneos?" e completa "Precisamente por serem povos de raças misturadas poderiam constituir um corretivo dinâmico aos racismos de todos os tipos" (2003, p. 366).
Os prejuízos dessa abordagem engendram apagamento de processos de violência racial e de gênero. Esquece-se que as estruturas do racismo e sexismo permeiam as famílias miscigenadas e criam tensões na ordem cotidiana e na formação dos indivíduos.

Se no contexto acadêmico sul-africano pesam os apagamentos sobre o contexto das mulheres, na luta contra o apartheid tornam-se os homens os únicos símbolos dessa luta antirracista (NDEBELE, 2003; GASA, 2007; BORGES, 2013). No contexto brasileiro, tanto as questões raciais como as de gênero estão esquecidas nas análises sobre processos socais que consideram o mestiço como o brasileiro por excelência. Ao mesmo tempo em que essas categorias miscigenacionistas excluem a participação negra da brasilidade, ou a relegam a um espaço caricatural (samba, futebol e música), elas também conferem às mulheres um espaço secundário na construção das histórias e saberes (AGUIAR, 2000; BERNARDINO, 2002; BORGES, 2013). No ocidente moderno, como tem alertado Oyèrónkẹ Oyěwùmí (1997), a forma de experienciar o mundo quase que exclusivamente pelo sentido da visão produz binarismos que tendem sempre a apagar o lado oposto do que se é visto - como no caso do binarismo de gênero que tende sempre a apagar as mulheres dos processos históricos. Entenderemos mais a diante, portanto, como a categoria e a imagem do candango agenciou e ocultou os corpos negros e de mulheres na construção da história de Brasília. Antes, contudo, voltaremos às remoções ocorridas deste lado do Atlântico.

\subsection{Ceilândia: memórias da remoção}

As remoções das favelas existentes ao redor de Brasília, durante e logo após a construção, fizeram parte de uma política de estado com o pretexto de assegurar a saúde e segurança das populações. No entanto, o fornecimento desses recursos básicos à manutenção da vida foram lentos e graduais. Residências dignas, água potável, saneamento básico, só alcançaram a cidade de Ceilândia depois de 1980, o plano de infraestrutura da cidade só será elaborado no final de 1974, ou seja, 3 anos após o início das remoções (SECRETARIA DE GOVERNO DO DISTRITO FEDERAL, 1974).

Segundo relatórios oficiais, a remoção desabrigou cerca de 80 mil pessoas durante os anos de 1971 e 1972. A Campanha de Erradicação de Invasões promovida pelo governador Hélio Prates tentou primeiramente convencer as famílias do IAPI através do slogan "A Cidade é uma 
Só" com filmagem de um vídeo de crianças daquela vila cantando um jingle nunca recuperado, mas representado recentemente no docudrama homônimo dirigido por Ardiley Queirós (2013). A estratégia não surtiu efeitos e a solução encontrada foi a remoção forçada das famílias em março de 1971, mesmo sem a construção das casas de alvenaria. Como relata Dalva Afonso N. Rodrigues, uma das primeiras moradoras da Ceilândia, em entrevista realizada ao Programa de História Oral do Arquivo Público do DF:

(SR) - Agora, chegava aqui dona Dalva, chegava aqui em Ceilândia, só estava o ....

(DR) - Cerrado.

(SR) - Cerrado. Como é que vocês faziam assim que chegava aqui, tinha que organizar logo alguma coisa para acolher a família.

(DR) - A começar que tinha que limpar o terreno.

(SR) - Certo.

(DR) - Tinha uns toquinhos muito pequenininhos, mas nem se via por causa do cerrado.

(SR) - Ah sim! demarcando o terreno.

(DR) - Demarcando, a gente tinha que limpar para construir, foi no mês de dezembro, chovendo demais.

(SR) - Demais nessa época.

(DR) - E nós ficamos onze dias debaixo de chuva. (RODRIGUES, 2002, p. 10).

Esse registro sobre o modelo das remoções também é encontrado num relatório produzido pela Secretaria de Serviços Sociais e pelo Departamento de Habitação Social de 1973. Os barracos foram remontados pela comunidade ou, quando as líderes familiares eram viúvas, por funcionários da administração; não houve, portanto construção prévia de residências de alvenaria (SECRETARIA DE SERVIÇOS SOCIAIS DO DISTRITO FEDERAL, 1973, p. 36). Aliás, a Secretaria de Comunicação Social da época registrou em fotografias esse modelo de remoções feitas durante o ano de 1971 como verificamos nas Figuras 2 e 3 :
Figura 2: Chegada à Ceilândia em fotografia registrada pela Secretaria de Comunicação Social.

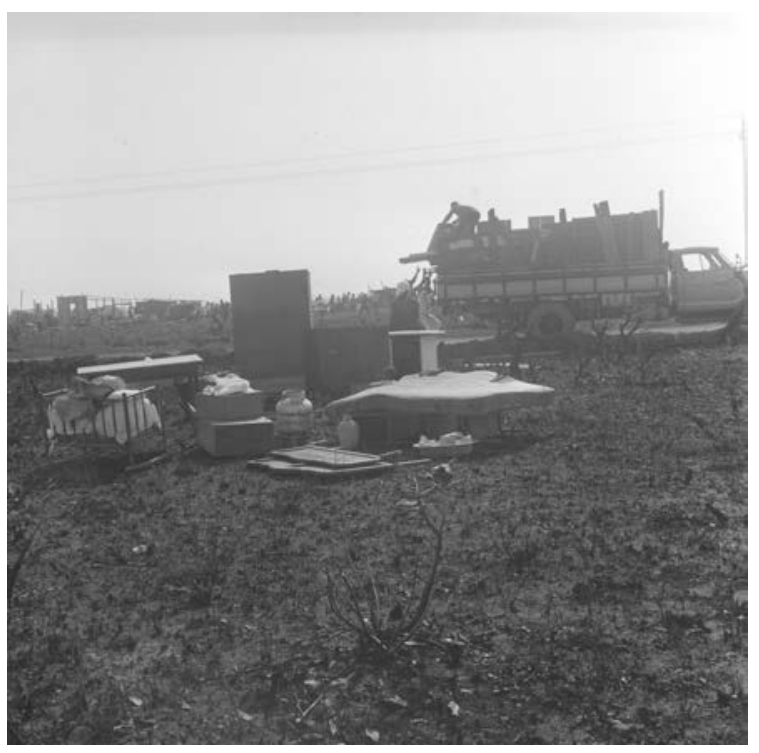

Figura: Arquivo Público do Distrito Federal, 1971.

\section{Figura 3: Montagem dos barracos}

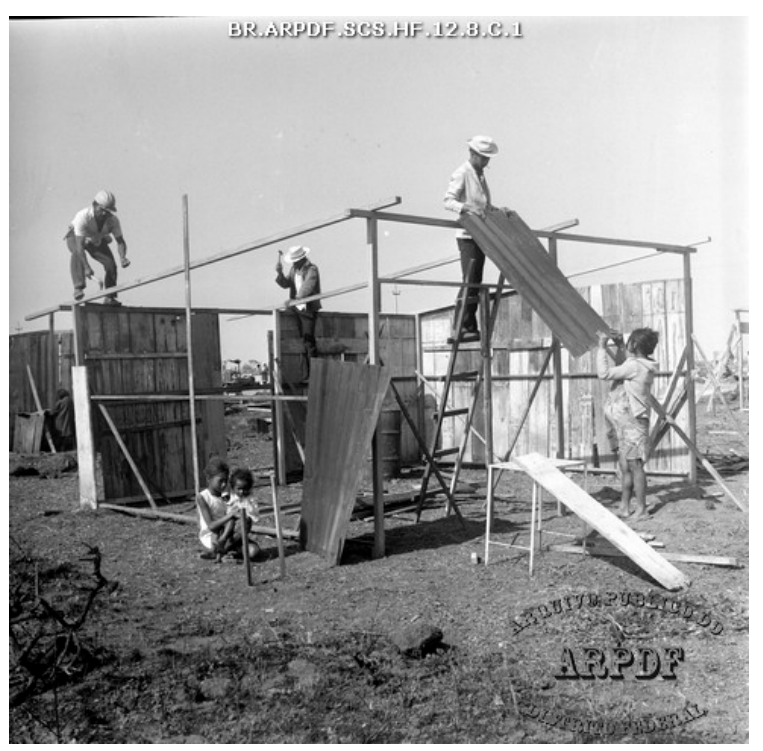

Fonte: Arquivo Público do Distrito Federal, 1971.

A história da chegada e do estabelecimento no Distrito Federal antes da Vila IAPI e da Ceilândia, também é marcada por uma série de acontecimentos que envolvem relações sociais complexas, de vínculos afetivos ou de relações desiguais de trabalho. Antônia Alves da Silva, conhecida como Toinha, é uma das nordestinas que encontramos na pesquisa do projeto de história oral. Ela narra sua chegada, as dificuldades enfrentadas e as redes de parentesco e afetividade que se criavam no ambiente da nova cidade:

(AS) - A minha chegada aqui no início foi muito cruel, eu cheguei aqui um dia 5 da tarde, quando foi 6 horas já estava interna- 
da.

(SR) - Porquê?

(AS) - Eu tomei um banho na divisa e eu não estava bem de saúde, então fiquei mal. Tomei remédios no hospital.

(SR) - Ficou com resfriado muito forte?

(AS) - Foi, eu fiquei toda entubada, eu fiquei dois meses e quinze dias internada, foi muito triste, mais eu não desisti, de lá do hospital... que eu vim para a casa de uma afilhada, de uma madrinha de fogueira minha, olha o parentesco que a gente tinha. Ela era afilhada da minha madrinha de fogueira e chegando na casa dela já fui me internar, lá no hospital, aquelas pessoas que cuidavam de mim, gostaram de mim, inclusive a copeira me levou para a casa dela.

(SR) - Que bacana!

(AS) - É, eu fiquei na casa dela 2 anos, trabalhando pela comida e era babá dos filhos dela, aí de lá eu... (SILVA, 2002, p.6).

Como vemos, afora essa rede de apoio criada a partir dos vínculos afetivos de pessoas próximas da região de origem, existia outra rede que cooptava essas mulheres recém-chegadas para o trabalho doméstico em relações que dissociam autonomia individual e trabalho. A história de Toinha, como de outras mulheres chegadas ao DF, passa também pela violência de gênero com o abandono do marido logo após a gestação:

(AS) - Não, quando eu fui prá Vila nós já tínhamos separado, no Gama mesmo, ele foi embora e eu fiquei com duas crianças.

(SR) - Sozinha para cuidar.

(AS) - É, você vê se... 69, que é aquela que está aqui, ela nasceu em julho de 69 , e a outra no dia 22 de dezembro de 70, então bem perto uma da outra, fiquei com essas duas meninas, eu dei a mais nova. Não tinha condições.

(SR) - Muito sacrifício?

(AS) - É daí... quem me acolhia tinha dificuldade de acolher as crianças, a mulher que eu deixava elas para poder ir trabalhar, a mulher queria tomar a mais nova, aquela ali, quando era três horas, já tinha que estar deitada sem ter direito de olha para nada. E ela só falava comigo se a mulher mandasse ela falar, e já estava lutando para tomar a mais nova, quando as vizinhas me falaram que ela queria tomar a menina, falei 'mas não vai tomar mesmo.' Eu dei para uma pessoa que podia criar e fui para Vila do IAPI só com ela.

(SR) - Só com a mais velha.
Nesse quadro de relações sociais que tecem uma rede entre indivíduo e sociedade, a "vulnerabilidade feminina encontra-se fortemente vinculada às [...] formas de exercício de poder (estatal, público e doméstico)" (BORGES, 2011, p. 210). Pensando a cidade moderna e seu surgimento, nos deparamos com a objetificação dos corpos, que são dispostos da maneira mais adequada para o serviço de outros corpos cuja historicidade Ihes confere poder. No caso de Toinha, não houve opção de lugar para se abrigar: tratada como objeto, trabalhava como babá para se alimentar e ter um teto. Ao mesmo tempo, esse corpo é abjeto quando colocado na relação dominante $\mathrm{x}$ dominado:
"a sociedade designa posições de limi- tes claros para os corpos que devem ser controlados, vigiados, contidos e re- jeitados. Na garantia da identidade he- gemônica, surge a necessidade da pro- dução da diferenciação, que transforma o 'outro' em lixo" (VIEIRA, 2014).

A pesquisa de Nanah Vieira (2014) sobre a atual situação de mulheres negras empregadas domésticas no Distrito Fereral exemplifica e nos leva a pensar como esse corpo objeto é, ao mesmo tempo, abjeto. Um corpo com fronteiras sociais e raciais bem estabelecidas. Nas linhas que se seguem perceberemos como essas fronteiras foram fomentadas, não só socialmente, mas por meio de uma tecnologia estatal e política. A definição da Faixa de Segurança Sanitária e a história do conceito candango atrelado às especificações histórico raciais desse corpo é outro exemplo de como se constituem processos frutíferos em questão de segregação racial no Brasil. Algumas vezes encontrando similitudes com processos ocorridos na África do Sul.

\section{Faixa de Segurança Sanitária: ou as Group Areas Act do candango.}

\subsection{Os limites físicos}

A escolha do local para a criação da Ceilândia obedeceu a uma distância considerável do centro. No relatório de 1973, dentre as justificativas elencadas para a escolha do território observamos o ponto: "área localizada fora da faixa de segurança sanitária" (SECRETARIA DE SERVIÇOS SOCIAIS DO DISTRITO FEDERAL, 1973, p.24). Mas o que seria a Faixa de Segurança Sanitária? Durante as pesquisas no Arquivo Público do Distrito Federal, encontrei a ata de reunião da Novacap que determinava, durante reuniões em junho de 1958, estudo para o balizamento da área, sob responsabili- 
dade de Adroaldo Junqueira Ayres (NOVACAP, 1958). Após o estudo, toda construção e doação de terra para dentro dos limites da faixa, só poderia ocorrer sob autorização do Conselho Executivo dessa instituição. Com frequência. o discurso usado pela administração para a criação dessa faixa foi o de preservação ambiental das águas de Brasília, mas é possível que a delimitação esteja relacionada com a criação e a distância que as futuras cidades-satélites deveriam manter do centro.

É interessante perceber como a Faixa foi definida exatamente no mês da chegada de famílias nordestinas fugidas da seca de 1958, e que no mês seguinte Taguatinga, primeira satélite, seria criada fora dos limites da segurança sanitária para abrigar os moradores da Vila Sarah Kubitschek. Outro ponto a se destacar é o fato de as ações para tratamento de água e esgoto para Asa Sul e Asa Norte (bairros centrais de Brasília) serem executadas muito tardiamente. Ou seja, até 1977 nenhuma das estações de tratamento de água dessas áreas tinha sido concluídas e os dejetos humanos eram todos lançados no Lago Paranoá (HOLSTON, 2010, p. 334). Se a Faixa de Segurança Sanitária tinha como alvo a preservação do lago, por que só se executaram as obras de tratamento de água depois dos anos 90 ?

$\mathrm{Na}$ ótica da sanitização dos centros, todas as formas de vida consideradas prejudiciais e indesejáveis são eliminadas. Essa eliminação não é feita de maneira aleatória. Existe um complexo jogo de delimitação, de especificação e de conceptualização das formas de vida. Criando e recriando "sub-humanidades", o exercício do poder produz formas mais vulneráveis engendrando assassinatos diretos e indiretos, "civilizando" as formas de produção de morte baseadas na similitude e alteridade.

$\mathrm{Na}$ África do Sul, onde as teorias e discussões raciais de caráter eugênico prevaleceram, a divisão de seres humanos foi assumida nas políticas de Estado - diferentes identidades raciais forjadas para determinação de espaços. Africans, indians, whites e coloureds foram estereotipados no âmbito público e estatal, como destaca Diana Mafe (2013). Com essas identidades já circunscritas, as leis de permanência do centro e os passes de acesso tornaram-se exequíveis. As distâncias criadas entre Johanesburgo e Soweto obedecem a uma ordem física e imaginária; o poder do segregacionismo reside na sua potência de criar ao mesmo tempo fronteiras e sub-humanidades. O planejamento urbano do apartheid é executado pen- sando no tipo de corpo objeto/abjeto que ali deve permanecer. Não por acaso, o segundo item do Goup Areas Act (1950) irá tipificar esses tipos corpóreos.

\subsection{Os limites imagéticos}

No Brasil, tanto a historiografia quanto o senso comum trataram essa exclusão pelo viés social e optoaram pelo ocultamento do processo de formação da cidade modernista intimamente conectado com a normatização e o racismo. James Holston (2010) entende que a estratificação era definida por meio dos conceitos "pioneiro" e "candango", sendo pioneiro todo aquele funcionário de estado escolarizado e candango o trabalhador não escolarizado e pobre. Porém, se analisarmos o conceito e sua etimologia na história, perceberemos que essa separação contém um aspecto racial, passado desapercebidamente graças à ideia de nação miscigenada.

Candango tem origem na palavra ka-ndongo, usada primeiramente na língua kimbundu, falada pelos Mbundu no sudoeste da Angola para se referenciar ao português como "pequenos", "desprezíveis", "vís". No kimbundo o prefixo "ka" flexiona os nomes no diminutivo enquanto "ndongo" é uma referência à região homônima (CHATELIAN, 1888, p. 8). No século XVII, as invasões portuguesas na costa angolana empreenderam guerras sem precedentes para captura de escravizados e escravizadas. Entre 1605 e 1641 "comunidades inteiras desapareceram e as guerras começaram a despovoar o Ngongo a um ritmo alarmante" (BIRMINGHAM, 1965 , p. 34). Após a invasão portuguesa os mbundu passaram a designar de forma depreciativa os portugueses como os "pequenos que vêm do Ndongo". Com o passar do tempo a palavra adquire variáveis como cangongo, na Bahia (AURÉLIO, 1948) e vai designar alguém que vem de fora numa relação do interior/litoral sem deixar o viés depreciativo. No Dicionário da Língua Portuguesa de Augusto Moreno Cardoso (1945) encontramos definições como: "Candango, s.m. Bras. Nome com que os Africanos designavam os Portugueses || Gir. Tipo desprezível ou defeituoso". Outras palavras similares também se aproximam do sentido de desprezível: "Candongo, adj. Provinc. Mal feito" (CARDOSO, 1945).

Ora, se pensarmos no espaço Atlântico, na formação do Brasil enquanto maior perpetrador do sistema escravista e no desembarque de quase dois milhões de escravizados no litoral brasileiro só no século XVIII (ALENCASTRO, 
2001), podemos considerar uma inversão e delimitação de quem são os provenientes do Atlântico. Se para os mbundu os kandongo eram os portugueses, que vieram do mar causando destruição, aqui, desse lado, os candangos eram o resultado de negras e negros africanos transformados em mercadoria, atravessados no oceano e vendidos nos portos.

De fato, Holston admite que a palavra passou a ser sinônimo de mestiço, mulato, cafuzo e "mais precisamente, a mescla de tipos raciais brasileiros, o mestiço de um mameluco (filho de índio e branco) e do negro" (2010, p. 209). O problema é que, mesmo percebendo essa origem etimológica, as referências historiográficas reservam ao termo um nivelamento social, perdendo seu caráter racial no contexto brasiliense:

Como essas misturas raciais compõem uma grande parte da população sertaneja brasileira, a palavra "candango" tornou-se um trabalhadores itinerantes pobres que o interior produz em grande quantidade. (HOLSTON, 2010, p. 209,210).

A interpretação histórica entende que, graças à miscigenação, o fator racial desapareceu das exclusões, foi nivelado por sua condição social. Esqueceu-se do passado recente pósemancipação e como os processos de conquista dos direitos e da cidadania de negros e negras no Brasil ocorreram de forma diferente, como têm destacado Ana Flávia Magalhães Pinto (2014) e Flávia Fernandes de Souza (2016).

Com efeito, se olharmos os discursos e as representações feitas sobre o candango, encontraremos a estratégia nacional e unificadora: "candangos são todos que vieram para Brasília". Mas assistiremos também à marca da diferença. Na edição especial de 1960 sobre a mudança, a Revista da Companhia Urbanizadora

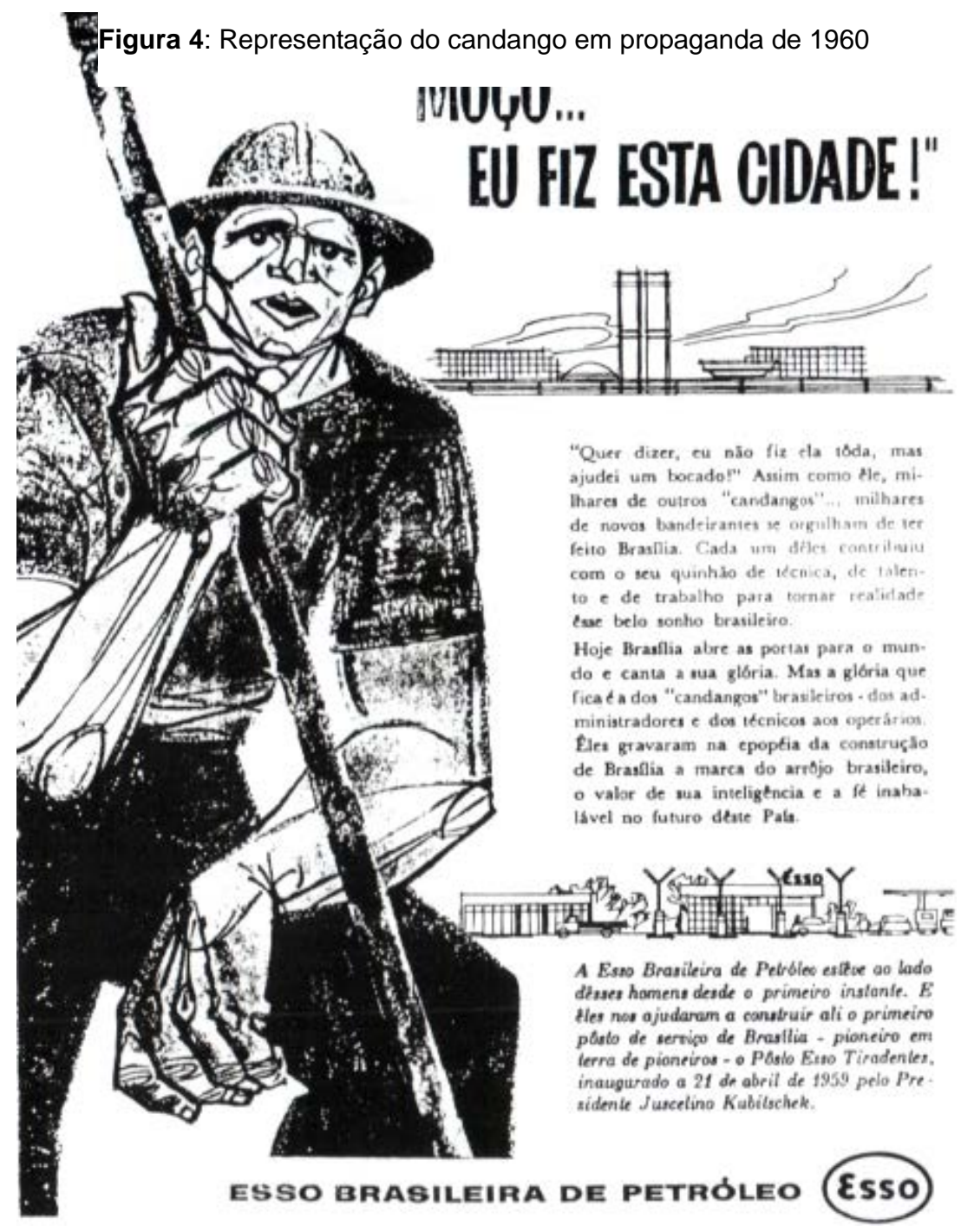

termo geral para as pessoas do interior em da Nova Capital (Novacap) reproduziu um disoposição ao litoral, e especialmente para os curso do então presidente da companhia, Israel 
Pinheiro, onde o candango aparece distinto dos "funcionários, dos técnicos, dos diretores, dos conselheiros e do presidente" (Novacap, 1960, p. 4). Já Juscelino Kubistchek se inscreve como "candango, a quem me orgulho de pertencer" (Novacap, 1960, p. 6).

Holston é capaz de abranger a diferença entre candangos e pioneiros na prática - salários, moradia, condições de permanência - a despeito do discurso unificador (2010, pp. 212-256). Mas, deixa-se enganar pela ideia da ausência do racismo devido ao processo miscigenacionista brasileiro. Como vemos (Figura 4), o candango representado é dono de uma masculinidade negra animalizada ou hiperbólica: alto, forte, corpulento, de lábios grossos e nariz negroide, mãos maiores que a circunferência da própria coxa e os dedos tão largos quanto o cabo da ferramenta que sustenta. No imaginário colonizador a figura do negro foi transformada, criouse uma máscara de infra humanidade, teceu-se esse corpo por meio de "mil pormenores, anedotas, relatos" (FANON apud MBEMBE, 2014, p. 192). Ao mesmo tempo, essa figura difundida do candango enquanto imagem masculinizada exclui, por si só, as mulheres do processo de construção da cidade, como se ela fosse exclusivamente o fruto do trabalho masculino. $\mathrm{O}$ documentário Poeira e Batom (2011), de Tânia Fontenele, ajuda a pensar como a participação das mulheres - que se autodenominam candangas - foi ativa na dinâmica da nova capital.

Além disso, esses corpos de mulheres e homens negros, não existem sem a capa colonial. Sombra dentre vários olhares, estão inseridos na economia de um comércio perverso, pois só existem para seu funcionamento (o que seria de Brasília sem os candangos e candangas?), omissão e cegueira (satélites e townships que ocultam do centro quem não deve ser visto?). Lembrando:

Ver não é a mesma coisa que olhar. Podemos olhar sem ver. E não é certo que aquilo seja efetivamente aquilo que é. Olhar e ver tem em comum solicitar esse juízo, encerrar aquilo que vemos ou aquilo que não vemos em inextrincáveis redes de sentido - as armadilhas de uma história. Na distribuição colonial do olhar, existe sempre um desejo de objetivação ou de supressão, um desejo incestuoso, assim como um desejo de posse ou, até, de violação. Mas o Olhar colonial tem também por função ser o véu que esconde essa verdade. O poder da colônia consiste portanto fundamentalmente no poder de ver ou não ver, de ser indiferente, de tornar invisível aquilo que não podemos ver [...] podemos então dizer que na colônia, quem decide o que é visível e o que deve ficar invisível, manda. (MBEMBE, 2014, p. 193).

O Distrito Federal escolheu não ver negras e negros. Na prática, circunscreveu seus limites com a Faixa de Segurança Sanitária, criando uma distância própria para o corpo estereotipado em suas características: o candango, homem, aço, trabalhador braçal. Na escrita historiográfica, nivelou todos sobre o aspecto social. Guardadas as particularidades, processos que rompem as barreiras atlânticas, antecedem e retrocedem neo tempo e aproximam as experiências do apartheid em Brasília e Johanesburgo.

\section{Considerações}

E, afinal, o que essas cidades podem nos dizer? Primeiramente que existem diversas instâncias de exercícios do poder que limitam a soberania da vida das pessoas impelindo condições de vulnerabilidade a que devem ser submetidas. Depois, nos dizem sobre a escolha e a determinação de onde serão estabelecidos os contatos, quem pode ou não ocupar espaços centrais ou a quem são destinados os espaços periféricos, em outras palavras, quem deve fazer viver e quem pode deixar morrer através do racismo institucional. Revela como nos territórios póscoloniais uma necropolitica é aplicada definindo os inimigos - habitantes da fronteira, pertencentes a uma infra humanidade - que podem e devem ser aniquilados numa precisão civilizada para garantia de segurança dos "humanos propriamente ditos".

Relacionar Brasil e África do Sul é, portanto, um exercício para não deixarmos isoladas histórias e experiências aproximadas. Pensar Soweto e Ceilândia, esses dois lugares tidos pelo centro como duas esquinas do mundo, é também encontrar pontos de convergência nos mecanismos de exercício do poder sobre os corpos negros e africanos, a delimitação das fronteiras desses corpos, a arquitetura e o urbanismo que tornam as vidas limitadas. Tendo sempre em mente, como já foi dito acima, a observância das particularidades das construções dos tipos raciais e racistas lá e cá.

Contudo, não devemos relegar nossas narrativas ao sofrimento, às mazelas e às incapacidades. É preciso reconhecer os sujeitos dessas cidades enquanto produtores de saberes, práti- 
cas e vivências que lhes dão sentido ao mundo. Fazendo isso, escaparemos, talvez, da armadiIha em que o "historiador" dita, produz e traduz toda as experiências perpetrando um sistema em quem só um ganha (o acadêmico) com o insucesso do outro (o sujeito de estudo). Numa oposição dada no momento das relações de produção acadêmicas uma solução possível é construir - com mulheres e homens dessas cidades - saberes, escritas, formas narrativas, que se multipliquem em futuros e possibilidades diversas, abrindo possibilidades que fogem ao fatalismo de uma história que se repete.

\section{Agradecimentos}

Primeiramente às minhas avós, Maria Eustáquia e Lúcia, sem as quais não haveria possibilidade de construção dos conhecimentos prévios para pensar esse artigo. A toda equipe do Arquivo Público do Distrito Federal, em especial à Tereza Eleutério, Rita Rocha e Ester Eiko. A FAP$D F$, pelo apoio da visita técnica realizada em setembro de 2017 na Universty of the Witwatersrand em Joanesburgo. A toda equipe do Historical Papers Archives, em especial a Sr. Zofia Sulej. As professoras e professores Antonádia Borges, Maria Fernanda Derntl, Richard Pithouse e Anderson Oliva. Aos amigos e amigas Thânisia Marcella, Lia Maria, Jonathan Dutra, Leandro Bulhões, Paique Santarém, Gregório Zambon e tantos outros que são coautores dessa pesquisa ao compartilhar experiências e pensamentos que estao para além dos livros.

\section{Referências}

\subsection{Fontes Primárias}

ÁFRICA DO SUL. Goup Areas Act, 1950.

Arquivo Público do Distrito Federal, Fundo Novacap, Nov. B. 2. 3. 0056.

Arquivo Público do Distrito Federal, Fundo Novacap, Nov. d. 4. 2. z. cx(1). 41d.

A CIDADE é uma só?. Direção: Adirley Queirós. Fotografia: Leonardo Feliciano. Ceilândia: 400 filme \& 5 da Norte Ceicine, 2013. 50 min. Disponível

em:

$<$ https://www.youtube.com/watch?v=7uS4YnaP WLU>. Acesso:12 jun. 2017.

BRASIL. De Brasília. Brasília: Edição Arquitetura \& Urbanismo, 1960.

BANCO sai preto fica. Direção: Adirley Queirós. Ceilândia: Vitrine Filmes; 5 da Norte \& Trocar, 2015. 1 DVD (93 min). ral, 1974.

Secretaria de Governo do Distrito Fede-

Secretaria de Serviços Sociais do Distrito Federal, 1973.

CARDOSO, Augusto Moreno; MACHADO, José Pedro. Grande Dicionário da Língua Portuguesa. Lisboa: Editorial Confluência, 1945.

CORRIGALL, Marry. Rebuilding a Community. Johannesburg: European Commission, 2008. disponível em:

https://ec.europa.eu/europeaid/sites/devco/files/ article-marycorrigal_en.pdf

FERREIRA, Aurélio Buarque de Holanda. Pequeno Dicionário Brasileiro da Língua Portuguesa. Rio de Janeiro: Editora Civilização Brasileira, 1948.

Historical Papers Archives of University of the Witwatersrand, History Workshop Photographs, 27(4).

MOHKINI, Victor. Interview Sophiatown Removals. Disponível em: https://archive.org/details/SophiatownRemovals ByVictorMokhini. Acesso em: 12 jun. 2017.

POEIRA e batom. Direção: Tânia Fontenele. Brasília: Produção Independente, 2011. 58min. Disponível em: < https://www.youtube.com/watch?v=9rxJUc8kbS k> $>$. Acesso: 14 jun. 2017.

SILVA, Antônia Alves da. Depoimento - Programa de História Oral. Brasília, Arquivo Público do Distrito Federal, 2002.

RODRIGUES, Dalva Afonso N. Depoimento Programa de História Oral. Brasília, Arquivo Público do Distrito Federal, 2002.

ROSENBURG, Dorothy. Interview for The Golden Yars. disponível em: https://wn.com/sophiatown_removals

\subsection{Fontes Secundárias}

AGUIAR, Neuma. Patriarcado, sociedade e patrimonialismo. Sociedede e Estado 15 (2), 2000, pp. 303-330.

ALENCASTRO, Luiz Felipe de. O Trato dos Viventes: formação do Brasil no Atlântico Sul. São Paulo: Companhia das Letras, 2000.

ALEXANDER, Peter; CERUTI, Claire; MOTSEKE, Keke; PHADI, Mosa; WALE, Kim. Class in Soweto. Scottsville: University of KwaZulu-Natal Press, 2013. 
BIRMINGHAM, David. The Portuguese Conquest of Angola. Londres: Oxford University Press, 1965.

BERNARDINO, Joaze. Ação Afirmativa e a Rediscussão do Mito da Democracia Racial no Brasil. Estudos Afro-Asiáticos, v.24, n. 2, pp. 247-273, 2002.

BORGES, Antonádia M. Explorando a noção de etnografia popular: comparações e transformações a partir dos casos das cidades-satélites brasileiras e das townships sul-africanas. Cuadernos de Antropoligia Social, n. 29, pp. 23-42, 2009.

BORGES, Antonádia M., Mulheres em suas casas: reflexões etnográficas a partir do Brasil e da África do Sul. Cadernos Pagu, n. 40, pp. 197-227, jan./jun. 2013.

DUBOW, Saul. Apartheid, 1948-1994. New York: Oxford University Press. 2014.

ELIAS, Norbert. O Processo Civilizacional: invegações sociogenéticas e psicogenéticas. $2^{\circ}$. vol. Lisboa: Don Quixote, 1990.

ERLANK, Natasha. Routes of Sophiatwon. African Studies, n.74, v.1, pp. 26-50, mar. 2015.

FANON, Frantz. Pele negra, máscaras brancas. Salvador: EDUFBA, 2008.

FONSECA-STATTER, Guilherme da. A África do Sul e o Sistema-Mundo: Da Guerra dos Bôeres à globalização. Lisboa: Gerpress, 2011.

FOUCAULT, Michel. Defender la Sociedad: Curso en el Collège de France (1975-1976). Buenos Aires: Fundo de Cultura Económica. 2000.

FREYRE, Gilberto; FONSECA, Edson Nery da (org.). Brasília: EdUnB, 2003.

GASA, Nomboniso. (ed.) Women in South African History. Baus'iimbokodo, Bawel'imilambo. They remove boulders and cross rivers. Cape Town, HRSC, 2007.

HOLSTON, James. Cidade Modernista: uma crítica de Brasília e sua utopia, 2 ed. São Paulo: Cia. das Letras, 2010.

HOUNTONDJI, Poulin J. Conhecimento de África, conhecimento de Africanos: duas perspectivas sobre os Estudos Africanos. Revista Crítica de Ciências Sociais, n. 80, pp. 149-160, 2008.

MAFE, Diana Adolesa. Mixed Race Stereotypes in South Africa and American Literature: Color- ing Outside the (Black and White) Lines. New York: Palgrave Macmillan. 2013.

MBEMBE, A. As Formas Africanas de AutoInscrição. Estudos Afro-Asiáticos, v. 23, pp. 179209, 2001.

MBEMBE, Achille. Necropolitica. España: Editorial Melusina. 2011

MBEMBE, Achille. Crítica da Razão Negra. Lisboa: Antígona, 2014.

NAIDOO, Yavini. Sophiatown Reimagined: Residents' Reconstructions of Place and Memory. African Studies, 74:1, pp. 98-122, mar. 2015.

NDEBELE, Njabulo. The Cry of Wine Mandela. Oxfordshire/OX: Ayebia Clarke, 2003.

OYĚWÙMÍ, Oyèrónkẹ́. The Invention of Women: making a african sense of western gender discourses. Londres: University of Minnesota Press, 1997.

PINTO, Ana Flávia Magalhães. Fortes Laços Em Linhas Rotas: Literatos Negros, Racismo e Cidadania na Segunda Metade do Século XIX. Campinas: Tese de Doutorado Unicamp. 2014.

SANTOS, Milton. Pobreza Urbana. São Paulo: Edusp, 2009.

SOUZA, Flávia Fernandes de. Trabalho doméstico: considerações sobre o tema recente de estudos da História Social do Trabalho no Brasil. Revista Mundos do Trabalho, vol.7, n.13, pp. 275-296, jan./jun. 2016.

VIEIRA, Nanah Sanches. O Trabalho da Babá: trajetórias corporais entre o afeto, o objeto e o abjeto. Brasília: Dissertação de Mestrado UnB. 2014. 